\title{
A Study on Socio-Cultural Practices during Menstruation among Adolescent Girls of Jabalpur District
}

\author{
Authors \\ Dr Shubhangi Nayak ${ }^{1}$, Dr Neelam Toppo², Dr Shashi Prabha Tomar \\ Dr Pradeep Kasar ${ }^{4}$ \\ Corresponding Author \\ Dr Shubhangi Nayak \\ Medical Officer, Chattarpur (MP)
}

\begin{abstract}
Background -Adolescence is defined by United Nations as the period of life from age 10 to 19 years Adolescents girls attain menarche during this phase. There are many socio cultural taboos practised during menstruation.

Objective- To assess the socio cultural practices by adolescent girls during menstruation in rural and urban areas of Jabalpur district.

Materials and Methods- $A$ cross sectional study was conducted in rural and urban areas of Jabalpur district. 400 adolescent girls (200 rural and 200 urban) were randomly selected as study subjects. A predesigned questionnaire was used.

Results- In our study average age of menarche in adolescent girls was $13.41 \pm 1.015$ years with the range of 10-16 years.. The social changes perceived by the adolescent girls after onset of menarche were mother becoming more strict, cessation of cooking, cessation of schooling, initiation of talk about marriage etc.

Conclusion- Onset of menarche had imposed various restrictions on adolescent girls even within the household. This difference was probably due to the lack of awareness and due to the association of more stigmas with menstruation in the rural areas as compared to the urban areas.
\end{abstract}

Keywords- Adolescents, socio-cultural taboos, menstruation.

\section{INTRODUCTION}

Adolescence is a phase of transition, where hormonal changes lead to onset of puberty, sudden and rapid physical growth and development of secondary sexual characteristics. Adolescent girls, have beginning of menstruation cycle in this phase. There are many socio-cultural taboos being practiced by females during menstruation.. Additionally, restricted mobility of girls often limits their access to health services and information on reproductive health.
The hygiene related practices of women during menstruation are of considerable importance, as they affect their health by increasing their vulnerability to infections, especially infections of the urinary tract and the perineum. Studies which were reported from India and other developing countries have highlighted the common practices which have prevailed among the adolescent females. This paper attempts to examine such socio-cultural practices by adolescent girls during menstruation in rural and urban areas of Jabalpur district. 


\section{MATERIALS AND METHODS}

The study was a Cross Sectional study. Ethical clearance was taken from college ethical clearance committee.

Study period: From $1^{\text {st }}$ June 2014 to $31^{\text {st }}$ October 2014.

Sampling technique - Multi stage random sampling technique was used.

Study subjects - 400 adolescent girls age 10-19 years were selected as study subjects. 200 girls were selected randomly each from rural and urban areas of Jabalpur district. Informed consent was taken from all respondents who volunteered for study.

A pretested, self-administered questionnaire was used for data collection.

\section{Statistical Analysis-}

Frequency distribution tables were prepared and statistical analysis was done using SPSS for windows version 20.0. Chi square tests and t-test were applied.

\section{RESULTS}

Age at menarche

Average age of menarche in adolescent girls was $13.41 \pm 1.015$ years with the range of $10-16$ years. Average age of menarche in adolescent girls was earlier in urban areas $(13.13 \pm 1.046)$ years as compared to rural areas $(13.76 \pm 0.858)$ years.

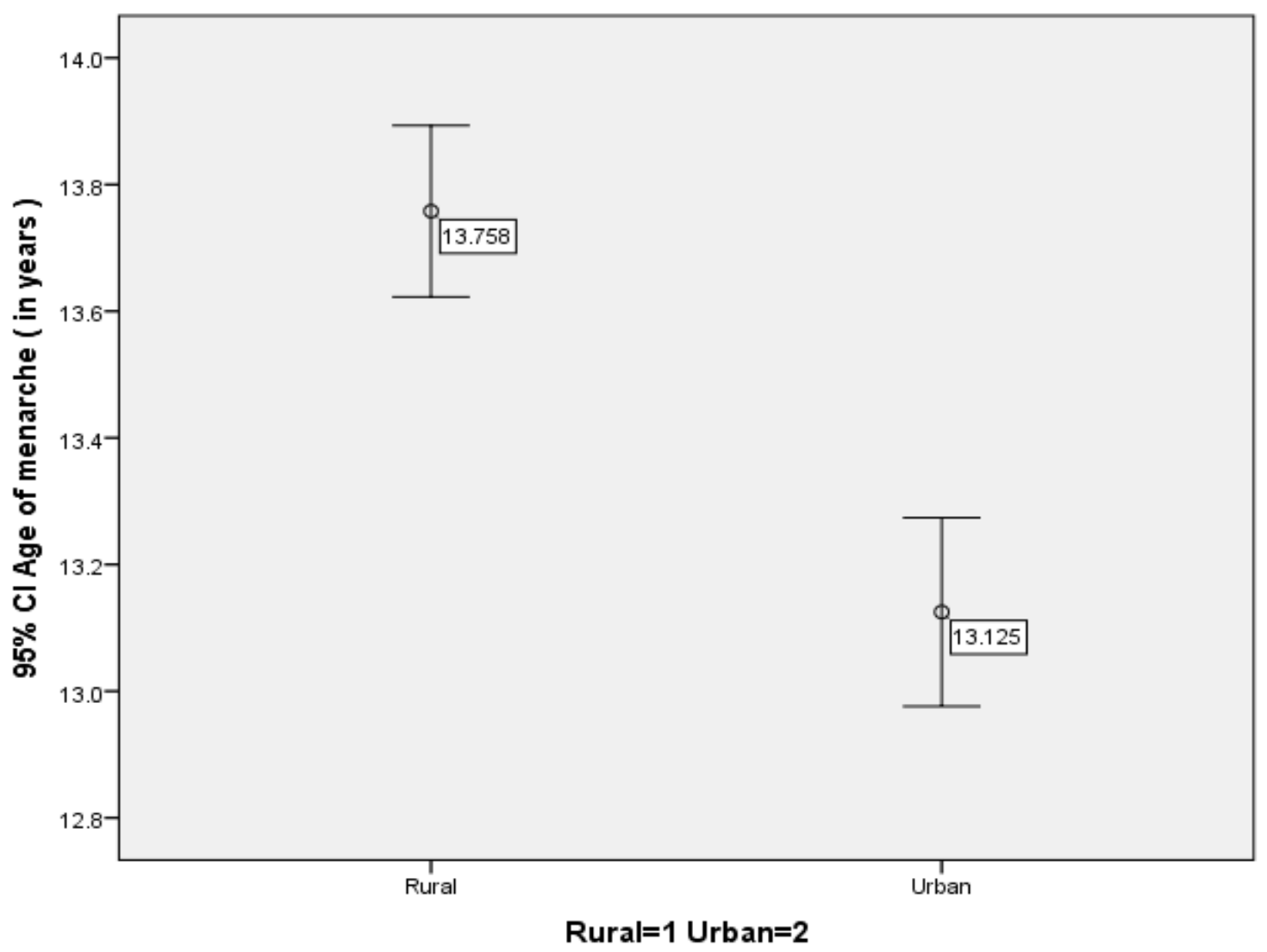

Figure 1. Error Bar Diagram Showing Mean Age at Menarche in Rural And Urban Areas

The difference in age of menarche between rural and urban adolescent girls was found to be statistically highly significant. ( $\mathrm{t}$ test assuming equality of variances was applied, $\mathrm{t}$ value $=6.090$, $\mathrm{p}$ value $<0.001)$. 
TABLE- 1 Distribution of Adolescents According to the Food Restriction Taboos During Menstruation

\begin{tabular}{|c|c|c|c|c|c|c|}
\hline \multirow{2}{*}{$\begin{array}{lr}\text { FOOD } & \text { RESTRICTION } \\
\text { TABOOS } & \text { DURING } \\
\text { MENSTRUATION } & \\
\end{array}$} & \multicolumn{2}{|c|}{ RURAL } & \multicolumn{2}{|c|}{ URBAN } & \multicolumn{2}{|c|}{ TOTAL } \\
\hline & NO. & $\%$ & NO. & $\%$ & NO. & $\%$ \\
\hline YES & 65 & $41.5 \%$ & 50 & $29.7 \%$ & 115 & $35.4 \%$ \\
\hline $\mathrm{NO}$ & 92 & $58.5 \%$ & 118 & $70.3 \%$ & 210 & $64.6 \%$ \\
\hline TOTAL & 157 & $100 \%$ & 168 & $100 \%$ & 325 & $100 \%$ \\
\hline
\end{tabular}

$\{\chi 2=4.809 ; P=0.028 ; d f=1 ; O R=1.667(95 \% C I=1.054-2.637)\}$

The table shows that $41.5 \%$ girls in rural areas and $29.7 \%$ girls in urban areas practiced different food restrictions during menstruation. Majority did not eat pickle, sour foods while some did not drink milk during menstruation.

TABLE-2 Distribution of Adolescents According to the Socio-Cultural Practices During Menstruatio

\begin{tabular}{|l|l|l|l|l|l|l|}
\hline \multirow{2}{*}{$\begin{array}{l}\text { SOCIO-CULTURAL PRACTICES } \\
\text { DURING MENSTRUATION }\end{array}$} & \multicolumn{2}{l|}{ RURAL } & \multicolumn{2}{l|}{ URBAN } & \multicolumn{2}{l|}{ TOTAL } \\
\cline { 2 - 7 } & No. & $\%$ & No. & \%o. & $\%$ \\
\hline Mother became more strict. & 67 & $42.6 \%$ & 70 & $41.6 \%$ & 137 & $42.1 \%$ \\
\hline Father does not talk. & 44 & $28.1 \%$ & 34 & $20.2 \%$ & 78 & $24 \%$ \\
\hline Not allowed to cook food. & 56 & $35.6 \%$ & 44 & $26.1 \%$ & 100 & $30.7 \%$ \\
\hline Not allowed to go to school. & 81 & $51.5 \%$ & 50 & $29.7 \%$ & 131 & $40.3 \%$ \\
\hline $\begin{array}{l}\text { Not allowed to go out and play and fetch } \\
\text { water. }\end{array}$ & 78 & $49.6 \%$ & 54 & $32.1 \%$ & 132 & $40.6 \%$ \\
\hline Not allowed to worship. & 142 & $90.4 \%$ & 126 & $75 \%$ & 268 & $82.4 \%$ \\
\hline Talk of marriage initiated. & 24 & $15.2 \%$ & 19 & $11.3 \%$ & 43 & $13.2 \%$ \\
\hline Consider it as a disease. & 25 & $15.9 \%$ & 7 & $4.1 \%$ & 32 & $9.8 \%$ \\
\hline Not allowed to come in front of visitors. & 27 & $17.1 \%$ & 4 & $2.3 \%$ & 31 & $9.5 \%$ \\
\hline Rebuked for being born as a girl. & 10 & $6.3 \%$ & 8 & $4.6 \%$ & 18 & $5.5 \%$ \\
\hline kept Isolated during menses. & 22 & $14 \%$ & 17 & $10.1 \%$ & 39 & $12 \%$ \\
\hline
\end{tabular}
$\left\{\chi^{2}=24.298 ; \mathrm{P}=0.007 ; \mathrm{df}=10\right\}$

The above table shows that $40.3 \%$ girls were not allowed to go to school, $40.6 \%$ girls were not allowed to go out and play and fetch water, $82.4 \%$ girls did not worship, $30.7 \%$ girls did not cooked food, $42.1 \%$ girls believed that mothers became more strict, $13.2 \%$ girls said that talk of marriage initiated in their family, $9.8 \%$ considered it as a disease, $9.5 \%$ girls were not allowed to come in front of visitors, $12 \%$ girls were kept isolated during menses, and $5.5 \%$ have been rebuked ever for being born as a girl.

\section{DISCUSSION}

Average age of menarche in adolescent girls was $13.41 \pm 1.015$ years with the range of $10-16$ years. Average age of menarche in adolescent girls was earlier in urban areas $(13.13 \pm 1.046)$ years as compared to rural areas ( $13.76 \pm 0.858$ ) years. Kotecha et al and Mittal et al also observed the similar median age for attainment of menarche among the girls i.e. 13 years. ${ }^{[1][2]}$ As per a Nigerian study, the mean age at menarche was 14.2 years with a range of 10-17 years. ${ }^{[3]}$ Das Gupta et al and Subhash B. Thakre et al reported 12.8 years as the mean age of menarche of the respondents. ${ }^{[4][5]}$ These findings were quite similar to our study.

$41.5 \%$ girls in rural areas and $29.7 \%$ girls in urban areas practiced different food restrictions during menstruation. Majority did not eat pickle, sour foods while some did not drink milk during menstruation. 
While as per A Dasgupta, only $15 \%$ girls did not practiced any restriction while $85 \%$ girls practiced different restrictions during menstruation. Among them, $50 \%$ girls did not eat certain foods such as sour foods, banana, radish and palm. The difference in findings depicted increasing awareness with time leading to decline in the food restriction practices. ${ }^{[4]}$

Different restrictions were practised by most of the girls in the present study, possibly due to different rituals in their communities, the same were practised by their mothers or other elderly female in the family, due to their ignorance and false perceptions about menstruation.

$40.3 \%$ girls were not allowed to go to school, $40.6 \%$ girls were not allowed to go out and play and fetch water, $82.4 \%$ girls did not worship, $30.7 \%$ girls did not cooked food, $42.1 \%$ girls believed that mothers became more strict, $13.2 \%$ girls said that talk of marriage initiated in their family, $9.8 \%$ considered it as a disease, $9.5 \%$ girls were not allowed to come in front of visitors, $12 \%$ girls were kept isolated during menses, and 5.5\% have been rebuked ever for being born as a girl.

The practice of the restrictions was significantly more among the rural girls as compared to the urban girls. This difference may be due to the lack of awareness in the rural areas and due to the association of more stigmas with menstruation in the rural areas as compared to the urban areas.

These findings were consistent with those of other studies ${ }^{[4,6,8]}$.

A Dasgupta, M Sarkar conducted a study on Menstrual hygiene in Kolkata and observed that $42.65 \%$ girls did not play, $33.82 \%$ girls did not perform any household work, $16.18 \%$ girls did not attend school, $70.59 \%$ girls did not attend any religious occasion, and $10.29 \%$ girls did not attend any marriage ceremony during the menstrual period and $6.25 \%$ girls believed it as a curse of God, $5 \%$ as a disease and $2.5 \%$ result of some sin. ${ }^{[4]}$

Maximum number of respondents commonly stated that, they had to remain isolated for 4 days without touching any other utensil except their own.
There were many girls who had to practice avoidance of religious activities during menstrual cycle in both urban and rural areas. Many girls also missed schools during menses and did not go outside.

\section{CONCLUSION}

Onset of menarche had imposed restrictions on the movements of adolescent girls more commomnly in rural areas. The social changes perceived by the adolescent girls after onset of menarche were mother becoming more strict, cessation of cooking, cessation of schooling, initiation of talk about marriage. This difference was probably due to the lack of awareness and due to the association of more stigmas with menstruation in the rural areas as compared to the urban areas.

\section{REFERENCES}

1. Kushwah S S, Mittal A. Perceptions and practice with regard to reproductive health among out-of-school adolescents. Indian J Community Med 2007;32:141-3.

2. P. V. Kotecha, Sangita V. Patel, V. S. Mazumdar, R. K. Baxi, Shobha Misra, Mansi Diwanji, Harsh Bakshi, Ekta Modi, Sandeep Shah, and Kalpita Shringarpure. Reproductive health awareness among urban school going adolescents in Vadodara city. Indian $\mathrm{J}$ Psychiatry. 2012 Oct-Dec; 54(4): 344 348.

3. Esimai O A, Esan GO. Awareness of menstrual abnormality amongst college students in urban area of Ile-Ife, Osun State, Nigeria. Indian J Community Med 2010;35:63-6.

4. Dasgupta A, Sarkar M. Menstrual Hygiene: How Hygienic is the Adolescent Girl?. Indian Journal of Community Medicine 2008; 33(2):77-80.

5. Subhash B. Thakre, Sushama S. Thakre, Monica Reddy, Nidhi Rathi, Ketaki Pathak, Suresh Ughad. Menstrual Hygiene: Knowledge and Practice among Adolescent School Girls of Saoner, 
Nagpur District. Journal of Clinical and Diagnostic Research. 2011 October, Vol5(5): 1027-1033.

6. Narayan KA, Shrivastava, DK, Pelto PJ, Veerapmmal S. Puberty rituals, reproductive and sexual health of adolescent school girls of south India. Asia Pacific Population Journal June, 2001; 16:225-38.

7. Omidwar S, Begum K. Factors which influence the hygienic practices during menses among girls from south India: A cross sectional study. International Journal of Collaborative Research on Internal Medicine and Public Health 2010; 2:411423. 